\title{
SECOND LANGUAGE ACQUISITION AND LINGUISTIC FREEDOM THROUGH DRAMA
}

\author{
Peter E. R. Jordan \\ Department of English, City University of Hong Kong \\ E-mail: pejordan@cityu.edu.hk
}

APA Citation: Jordan, P. E. R. (2015). Second language acquisition and linguistic freedom through drama. English Review: Journal of English Education, 4(1), 15-24

Received: 05-03-2015

Accepted: 08-10-2015

Published: 01-12-2015

\begin{abstract}
:
The important part played by drama in second language acquisition has long been appreciated. An active and inter-active teaching environment facilitates learning in a number of ways, by motivating and sustaining attention, as well as offering a secure environment for experimentation. Drama offers students a pro-active approach to learning, promoting a collective feeling of being in a shared enterprise. This paper discusses how drama can make a significant contribution to second language acquisition. In particular, I focus on the techniques of the Italian Commedia dell'Arte, the first truly professional theatre form to emerge in Europe in the mid-sixteenth century. Its core elements of improvisation and mask are highly effective tools in language learning, empowering students and allowing them to take ownership of the unfamiliar. Improvisation provides a dramatically engaging forum for experimentation that can help to overcome cognitive blocks and prioritise communication as the ultimate imperative. Masks which leave the mouth free for speech can help students overcome the natural inhibitions that often come with attempts to express oneself in an unfamiliar linguistic code.
\end{abstract}

Keywords: language acquisition, drama, improvisation, mask

\section{INTRODUCTION}

The important part played by drama in second language acquisition has long been appreciated. There is no doubt that an active and inter-active teaching context facilitates learning in a number of ways, but principally by motivating students, sustaining their attention and stimulating discourse. Drama offers just such a pro-active approach to learning, promoting a collective feeling of being in a shared enterprise and offering a secure environment for experimentation and role play. This is a crucial element as language is primarily a tool of communication with others.

Also, the role of enjoyment should not be underestimated. Students who are fully engaged and taking pleasure in participating in a drama exercise will find they have all the natural resources of concentration and imagination at their disposal.

Furthermore, the deployment of language combined with physical action harnesses visual memory and the body's natural muscle memory in the process of spontaneous recall. This is well understood in the theatre. Professional actors will often not be able to make sense of and secure their spoken text until it has been firmly linked to their actions and those of others in the play.

The emotional component of language is best explored in drama, which depends on a sense of 'inner truth' 
in order to induce the willing suspension of disbelief' in any given audience. 'Truth' in the dramatic sense equates with emotional truth, not literal truth. One does not have to kill people or urge others to kill in order to understand the jealousy of Othello or the ambition of Lady Macbeth. One does not have to kill oneself in order to appreciate and give voice to the intense all-consuming love between Juliet and Romeo.

This paper is the product of my more than thirty years' experience as both a theatre professional and a teacher, during which time I have come to understand that the skills associated with drama are inherently transferrable to language acquisition. Having frequently acted in foreign languages (Italian, German, Swedish, French and Cantonese), I have learned, at first hand, how the performance process can enhance linguistic skills in many ways. This is true of all theatre genres, but in particular I argue that the many techniques and traditions of the so-called Commedia dell'Arte provide the most comprehensive tool-set for facilitating second language acquisition. My long association with performing, directing and teaching the specific skills of this urgenre of Western drama has prompted deep reflection about its applicability to the complex process of second language acquisition.

\section{DRAMA TRAINING}

The first systematiser of the acting process as understood in the European canon that originated with the ancient Greek theatre, roughly 2500 years ago, was the Russian actor and director, Konstantin Stanislavsky at the turn of the twentieth century. He proposed that actors should draw on their 'emotional memory' in order to portray characters with a verisimilitude, known colloquially as 'realism'. Any given individual has a repository of past experiences, and a memory of the emotions generated by those experiences. According to Stanislavsky and his later interpreters, actors can draw on this reservoir of past experience in order to infuse their character's speech with emotional authenticity. Thus dramatic interpretation can assist in the delivery of speech with all the natural emphasis, intonation and cadence of everyday locution. For a detailed overview of Stanislavsky's theories and those of his later interpreters, a good starting point is Jean Benedetti's The Art of the Actor: The Essential History of Acting, From Classical Times to the Present Day.

Actor training also involves intense voice coaching that includes the technical aspects of voice production: diction, articulation and projection. A strong grounding in phonetics enables the student of acting, as much as the student of language, to master unfamiliar sounds and combinations of sounds through rigorous drilling and regular practice to train the vocal instrument (tongue, teeth, lips and vocal folds). Actors are often required to study a range of accents, both regional and national. With the help of a qualified accent coach, unfamiliar rules of pronunciation can be learned and reproduced with confidence and fluency. Opera singers routinely receive such training in order to be able to sing naturally and easily in various languages, despite not necessarily being conversant in the language. The process is almost identical to that of students of second languages, who have to learn an unfamiliar pronunciation and accent, in order to express themselves intelligibly and with authenticity.

Whilst the audio-lingual method of language teaching, inspired by 
ENGLISH REVIEW: Journal of English Education Vol. 4, Issue 1, December 2015

behaviourist psychological theories, has been much criticised, it continues to be applied successfully in schools, such as the Shenker Institutes, based in Italy. The method involves intensive drilling in the accurate reproduction of English pronunciation, breaking the sound of the language down into its component phonemes, even before the student understands the words being uttered. The rationale behind this approach is that speech in a second language can never be fully achieved if the sounds made are so distorted that the listener is unable to understand what is being said (Brown, 2000).

This process is underscored by the former leading voice coach for the United Kingdom's National Theatre and the Royal Shakespeare company:

The process we call speech is simply one of physically breaking up the voice into identifiable units called words. This process is done in the mouth with the lips, jaw, tongue, soft palate and facial muscles. It is very precise physical work and speech is one of the most balanced and complex muscular exercises the body performs (Rodenburg, 1998, p. 104).

Understanding the physical and muscular nature of speech can then help the actor (and student) to appreciate the inherent communicative qualities of the sounds produced. Thus,

Learning to work with consonants and vowels teaches you about the physical properties of words and how your articulation of them brings verbal strength... A common postulate you can make is: consonants = clarity of thought; vowels $=$ emotion. Pause, pace and intention are all embedded in the word. Remember that language is only partly intellectual. Speaking words clearly opens
ISSN 2301-7554

https://journal.uniku.ac.id/index.php/ERJEE

many more doors to the world of the mind, heart and soul (p. 106).

Obviously, the speaker must also understand what he or she is saying and must also understand the other person's reply. However, reaching a full and nuanced understanding of pronunciation and inflexion will greatly enhance comprehension. The truth of this has been confirmed to me indirectly on numerous occasions, when I have slipped into speaking English with a local accent, making the typical pronunciation mistakes made by the people I am talking to at the time, be they Italian or Chinese. Invariably, I have found that my interlocutor will compliment me on the 'clarity' of my English!

\section{COMMEDIA DELL'ARTE}

The above Italian phrase literally means 'comedy/theatre of the profession' or 'professional theatre'. It was originally coined by the eighteenthcentury playwright, Carlo Goldoni, as a rather dismissive term for the most popular form of theatre at that time. This genre of masked theatre originated in the mid-sixteenth century and is generally considered to be the first manifestation of a truly professional theatre, at least in Europe. Prior to its emergence, drama was performed exclusively by amateurs, either for their own private pleasure, or as part of religious ritual in celebration of specific festivals or, in the Christian era, to portray biblical events to a largely illiterate public.

As a result of collaboration between educated members of the Italian elite and lowly entertainers, a distinct form evolved that became fantastically popular and famed throughout Europe at all levels of society. William Shakespeare and his contemporaries 
during the 'Golden Age' of Elizabethan drama in the late sixteenth and early seventeenth century were aware of the early Italian professionals and it is very likely that they took inspiration from them to create drama that had a truly mass appeal.

The transition from amateur to fully professional drama involved a fundamental shift of focus. The priority of these actors was to induce spectators not only to watch and enjoy their performances, but also to pay for the privilege. Without income, they could not eat, and thus drama became predicated on communication over and above aesthetic or religious concerns. Typically, actors formed themselves into companies, who then travelled extensively from town to town in search of new audiences. The luckiest of these professional troupes received patronage from the nobility and from royalty, but the vast majority of acting companies depended on a peripatetic life, passing from one jurisdiction to another ever in quest of new sources of income. In the process of providing popular entertainment, they often took risks with their use of language. Ribald wordplay, frequently including scatological references, was an immensely popular form of wit that amused the masses, but angered some of those in authority.

The Catholic Church was especially critical of the early professional actors, not only because of the frequent use of vulgar language, but also because the actors were so popular that they were drawing the punters away from their religious devotions. In a sense, they were stealing the Church's audience; such was the enthusiasm they generated among their audiences, by speaking the everyday language of the common people. Incidentally, it is worth noting that the word, 'vulgar', comes from the Italian 'volgare', which originally signified 'vernacular', rather than the more pejorative sense that it has in English. At that time, all religious rituals were conducted in Latin, which was also the language of scholarship and diplomacy, whereas vernacular speech was the language of the people, the language of everyday interactions and conversations.

The Commedia dell'Arte was famed in particular for its improvised dialogue and masked stock characters, which conformed to three basic types: masters, servants and lovers. Of the masters, Pantalone is the most wellknown, just as Harlequin is the most famous of the servants. Typically, the young lovers would be the children of Pantalone and other master characters. This simple three-way categorisation of roles has echoes in the dramatic traditions of China, Bali, Japan and elsewhere. The use of masks also harks back to ancient forms of theatre to be found throughout Asia. The masks of the Commedia dell'Arte were moulded in leather to fit comfortably on different facial contours. They were always 'halfmasks', that is, the mouth was not covered, so that the actor could speak freely. Unlike more stylised forms of drama, the masks of the Commedia dell'Arte were particularly verbose. Dialogue was either improvised or delivered as monologues and duologues, often in forms of rhyming verse.

The available evidence from the mid-sixteenth century onwards, indicates that Venice, a polyglot melting pot of nationalities, was crucial to the development of the professional theatre. In a sense, the republic was a microcosm of the multilingual, or at least multidialectal, composition of the Italian peninsula at that time. Multilingualism and contemporaneity were undoubtedly 
ENGLISH REVIEW: Journal of English Education Vol. 4, Issue 1, December 2015

at the forefront of the development of secular theatre in the early modern era, when multi-tasking actors had to forge a recognisable and socially acceptable profession which was both a valid art form and remunerative. It is precisely this linguistic diversity coupled also with mask work, physicality and reality-based comedy that lends the Commedia dell'Arte to language acquisition through drama.

In spite of the obvious artifice of masks and stylisation, the characters of the Commedia dell'Arte were drawn from elements of real contemporary types. Many of them were associated with specific professions and specific cities and regions of Italy, and often expressed themselves in the local dialect. Pantalone was a rich old Venetian merchant, whilst Harlequin was depicted as an impoverished porter from the border town of Bergamo. Other characters included: the Doctor, a pedantic academic from Bologna, home of the oldest university in Europe; the Captain, a flamboyant, marauding Spanish mercenary; and Pulcinella, a slow-witted but often devious and belligerent citizen of Naples. The lovers typically expressed themselves in the Tuscan dialect of Florence, the language of Dante, which ultimately became the official language of Italy after the country's unification in 1871.

The ability to adapt to a variety of spaces and conditions, coupled with the need to communicate to a wide range of audience tastes, would have involved considerable forward planning that prioritised the technical demands of presentation, and a profound understanding of the differing perspectives of all the people that made up the complex social fabric of a culturally diverse cosmopolitan city, such as Venice. Small wonder then, that the professionals were subsequently able
ISSN 2301-7554

https://journal.uniku.ac.id/index.php/ERJEE

effortlessly to ply their trade throughout polyglot Europe and to communicate to people of different nationalities and cultures.

I shall now discuss in more detail the component elements of the Commedia dell'Arte - some of which have been mentioned briefly above - and the ways in which they can enhance second language acquisition.

\section{IMPROVISATION}

The use of improvisation and game playing stimulates spontaneity and the creative application of speech, with the added benefit of allowing the learner to take ownership of personal dialogue, even before grammar, syntax and vocabulary have been completely mastered. Moreover, the natural interactive flow of dialogue can be more easily reproduced in playing a role than in the dry call and response of a mechanical classroom exercise. In particular,

Classroom drama is most useful in exploring topics when there are no single, correct answers or interpretations, and when divergence is more interesting than conformity and truth is interpretable (Dervishaj, 2009, p. 55).

Giving students the opportunity and permission to mediate reality through their own observations and experience will enhance their ability to manipulate the linguistic tools at their disposal.

Simple rote learning certainly has an important part to play in the process, particularly in mastering unfamiliar cadence, intonation and stress. This is perhaps especially so for learners of English whose first language is not part of the Indo-European family. Mothertongue speakers of tonal languages, such 
as Chinese, Vietnamese and Thai are more likely than most to encounter difficulty in grasping the nuances of intonation, as used in English, where the slightest change of inflection can indicate a range of attitudinal positions. For example, the infusion of irony, scepticism or dismay into a commonplace phrase may hinge on the slightest of pauses, a barely perceptible rising tone, or a gentle stress on an operative word. Repetition of routine phrases in a dramatic setting can often help to elucidate and tease out these subtleties and sensitise the ear of the learner.

On the other hand, more freeform script-less acting exercises will enhance and encourage a greater degree of flexibility that allows for the natural improvisation of informal conversation. In a drama context, since the publication of Keith Johnstone's seminal Impro, such improvisation is nowadays almost universally considered to be essential to the building of a character, or role.

Extemporisation instils the sink-or-swim imperative to take the discourse forward in a meaningful way. A mutual commitment to maintaining the natural momentum of a conversation is essential in generating active complicity between interlocutors. Actors are taught to nurture this sense of 'give-and-take' as a discipline and a responsibility, without which communication breaks down.

It is important to emphasise that failure, inaccuracy and even occasional incoherence are all permissible as part of the learning process. Similar to Sherlock Holmes' dictum 'when you have eliminated the impossible, whatever remains, however improbable, must be the truth', actors often have to go through a sometimes painful journey of experiment and exploration before finally making sense of their roles, understanding their relationships to others and to the play as a whole. However, once this exhaustive exercise is complete, the performer will usually enjoy a feeling of assurance, a feeling that is mirrored by the language student in the throes of decoding the alien rhythms, phonemes and sentence structure of a second language. The experience, for both actor and student, can certainly be fatiguing, at times dispiriting, but with persistence even those who initially display little natural flair can begin to express themselves with confidence, if not aplomb.

Furthermore, improvisation naturally reproduces the spontaneity of real language with all its non-sequiturs, pauses, bridging words and phrases (e.g. 'well', 'actually', 'you know'), and sounds (e.g. 'um', 'er', 'hmm'). The actors of the Commedia dell'Arte frequently used a form of nonsense language known as 'grammelot', which can perhaps best be characterised as a vocal stream of emotionally meaningful, onomatopoeic but lexically dubious chatter. Nobel laureate Dario Fo, who has named the Commedia dell'Arte as one of his principal literary and performative influences, has deployed grammelot to great effect, particularly in his comic monologues. English is peculiarly rich with examples of onomatopoeia. Imitative vocalisations such as 'sizzle', 'hiss', 'bump', 'bang', 'crash', 'smash' and 'hiccup' have all now been graced with entries in the major dictionaries, having first entered the language as imitative sounds. Similarly, English has a long history of permitting the entry of neologisms into the language, from Shakespeare to Lewis Carroll and beyond to the contributions from other cultures. In addition to the ancient languages of Greek and Latin, modern English has also acquired, and continues 
ENGLISH REVIEW: Journal of English Education Vol. 4, Issue 1, December 2015

to acquire, much vocabulary from more distant linguistic sources around the world (e.g. Arabic, Hindi, Chinese, Japanese). It is important to emphasise this fact to students, in order to encourage them to 'take ownership' of a truly global language, which is in reality a hybrid of many original languages, including Norse, Danish, French and German. One has only to look at its idiosyncratic spelling to appreciate this fact.

\section{MASK}

The Commedia dell'Arte half-mask has two principal uses: to conceal and to transform identity. It also serves to amplify facial characteristics in order that these can be recognised from a distance. The act of concealing and thus transforming identity can often be of great benefit to language students, particularly those who are shy and reserved, either for personal or for cultural reasons. This is particularly the case in an Asian context where

frightened of losing face, any students from the Confucian-heritage cultures (CHC) dare not volunteer personal ideas, either for fear of being considered silly or for fear of making others feel humiliated ... allowing a person to save face is more important than telling the truth (Nguyen, Terlouw and Pilot, 2006, p. 7) .

Masks can confer the freedom to transgress cultural norms and pressures. By literally 'losing face' - concealing it under a mask - many students experience a feeling of empowerment, a sudden freeing from self-consciousness and a lack of confidence. In the process, they can discover a fluency and articulacy that eluded them previously.
ISSN 2301-7554

https://journal.uniku.ac.id/index.php/ERJEE

I have often encountered students who were painfully inhibited in their speech for various reasons, perhaps because they perceived their English to be less proficient than their classmates, or because they were embarrassed to utter a sentence without being absolutely certain that what they were saying was grammatically correct. Yet, once such students don a mask covering the face and, to a certain extent, the identity, they are frequently liberated from their selfconscious and self-imposed restraints. The mask confers permission to speak in any way you like, without concern for accuracy. Obviously, the ultimate goal of language teaching is precision and fluency, but exercises with masks can help some students to overcome their inhibitions and learn to express themselves meaningfully and with emotional authenticity. In this way, the imperative to communicate can be instilled and they can make English 'belong' to them as it already does to so many others around the world.

Indeed, it is only with this flexibility that English can keep its place as a global language. In the Anglophone world, there is no equivalent of the French Académie française, which oversees the use of the language in order to preserve its supposed purity. Only recently has the Académie relented on its ban of borrowings from English, such as, 'le week-end'. In the English-speaking world, there is no such institution to decree what we can or cannot say. It therefore follows that we can say anything, as long as successful communication is achieved in the process. This fact, once fully understood in all its implications, should be deeply empowering for all students of the language. 
Peter E. R. Jordan

Second Language Acquisition and Linguistic Freedom Through Drama

\section{REALISM}

In addition to the core elements of the Commedia dell'Arte: improvisation and mask, there are several other key components that are worth discussing briefly.

Despite the artifice, stylisation and simplification that is evident in the Commedia dell' Arte, the characters and narrative situations are grounded in reality. Obviously, the reality of Asia today will differ from that in sixteenthcentury Italy, but essential relationships of power, status and affection are recognisable the world over and throughout time. The realities of making one's way in the world, negotiating one's position in the social hierarchy, attempting to fulfil desires and to strive for contentment have not changed much over the millennia, even while the external contours of civilisation have been in a ceaseless state of flux.

\section{PHYSICALITY}

As already mentioned, from the outset, the Commedia dell'Arte practised multilingualism. Pantalone would express himself in the Venetian dialect; the Doctor in Bolognese; the servants in Bergamese; Pulcinella in the Neapolitan vernacular; and the lovers in the Tuscan dialect. The latter became the official Italian language in 1871, just as Putonghua was formally adopted as the official Chinese national language in 1932, or Bahasa Indonesia was declared Indonesia's official language in 1945. Nevertheless, the people of all three countries continue to use their local dialects. As a result of this historical situation, the Commedia dell'Arte has a strongly mimetic element that both traverses language barriers, and underlines, complements and facilitates speech and communication.
The use of gesture to underpin spoken language differs from culture to culture. With the mélange of Italian patois to be found, even to this day, the actors of the Commedia dell'Arte necessarily placed greater emphasis on other methods of communication, in particular through costume, movement and gesture. Present-day Italians are justly famed for their vigorous language of gesture that often convey very specific meanings (e.g. 'I'm hungry', 'That tastes good', 'I don't care', 'Watch out!', 'Let's get out of here', 'Nothing', 'Boring!', 'What are you talking about?', 'Money', 'You're scared', 'I'm not sure if you get my meaning' etc.). Conversely, the British or Chinese are typically less physically effusive, yet they too will underpin the meanings conveyed in speech with occasional gestures and other forms of body language. Gesture can provide attitudinal nuance and amplification to verbal speech, and aids memorisation. The use of gesture, freed up by the disguise of the mask, can not only enhance speech, but also help to relax the speaker. Nervousness and fear paralyse the mind. All actors have to overcome the fear of performance. Similarly, language learners are in a very real sense performing a role, when they attempt to speak in the language of an alien culture, and fear is a natural product of that attempt. So it follows that anything which relaxes will free up the mind and facilitate recall.

\section{AUDIENCE INTERACTION}

The modern theatrical notion of a 'fourth wall' - the pretence that the actors are unaware of the audience and are speaking as if they were alone on the stage - was unknown in the theatre of the Commedia dell'Arte, just as it is in many traditional Asian theatre forms. The actors were thus free to talk to and 
to interact directly with the audience. Also, by demolishing 'the fourth wall', actors have the twin possibility of being part of the action or stepping out and commenting on it. This is rather akin to the workings of Process Drama, sometimes used in language learning. The actor both lives in the moment of the scene, interacting with emotional commitment, or he/she may narrate diegetically, ever aware that the audience can answer back at some point. This is not unlike the linguistic and presentational skills required of the public speaker who may also have to deal with the interventions of hecklers. Thus, even speeches learned by rote can acquire a spontaneity and flexibility that exercises the speaker and gives him or her greater mastery of language and its application.

\section{'HIGH' AND ‘LOW' CULTURE}

The literature of the Commedia dell'Arte is an eclectic mix of literary sophistication and ribald speech. It celebrates both popular and elite culture. The irreverence that is everywhere apparent in this material, provides a broad palette of permissible behaviours and locutions. It is certainly true that "literary texts are often rich in multiple levels of meaning, and demand that the reader/ learner is actively 'teasing out' the unstated implications and assumptions of the text" (Lazar, 1993, p. 19). However, language arts should also be a means to achieving greater fluency in everyday speech and the mundanities of many everyday interactions.

\section{MUSIC AND SONG}

In keeping with its determination to entertain and delight as many people as possible, the plays of the Commedia dell'Arte contain many moments of song and dance. Song, in particular, is an extremely useful means for learning language, at least key phrases thereof. Through melodic connections, rhymes, rhythms and repetition, large tranches of text can be absorbed, retained and regurgitated at will. This is true of rhyming, metered verse in general, but song adds a further musical mnemonic element.

\section{COMEDY}

The early professional actors were driven by a need to attract and to hold the attention of a paying audience. Originally, they performed in a variety of genres, even tragedy, but most popular by far was comedy with its power to evoke the pleasurable effects of laughter, which is not only enjoyed by the individual, but also as a collective act. Thus, in time, the Commedia dell'Arte became associated exclusively with comedy. Common intuition, supported by many sociological and psychological studies, has confirmed the positive, healthful and pleasurable effects of humour and laughter. A comic event, such as a particularly amusing role-play or improvisation, is not only intellectually stimulating, it will also lodge more easily in the memory along with details of the actions and speech used.

\section{CONCLUSION}

A multi-modal approach - as can be found in the techniques and practices of the Commedia dell'Arte - undoubtedly facilitates and enriches the learning experience, increasing our ability to recall, adapt and interact in a wide range of contexts. Whilst drama, in all its forms, can certainly enhance and facilitate language teaching in the ways outlined above, a word of caution should be sounded. Many students will enjoy role-play, improvisation, singing and 
Peter E. R. Jordan

Second Language Acquisition and Linguistic Freedom Through Drama

movement, but there is nevertheless no guarantee that language will be acquired and consolidated in the process. All that can be said for sure is that the many tools encompassed by the rubric 'drama' are just that: tools. Their effective use is still subject to the expert application and guidance of the teacher, who will preferably also have a solid and complementary grounding in drama. When efficaciously deployed, drama can bring profound and lasting benefits in the acquisition, retention and expression of a second, and even third or fourth, language. Drama is, in a very real sense, a 'language art'. In the words of a respected Hong Kong educator, commentator and theatre practitioner:

engaging in the activities of language arts helps enhance the motivation of learning English, both within and outside the classroom. If students find the activities rewarding and they are learning the language at the same time, they will be willing to spend more time on them.... Thus with language arts activities, many more conditions for interesting and creative language learning and use can be created (Mok, 2001, p. 6).
The creativity and inspirational qualities of the teacher in facilitating this process is paramount.

\section{REFERENCES}

Benedetti, J. (2005). The art of the actor: The essential history of acting, from classical times to the present day. London: Methuen.

Brown, H. D. (2000). Principles of language learning and teaching ( $4^{\text {th }}$ ed.) New York, NY: Longman.

Dervishaj, A. (2009). Using drama as a creative method for foreign language acquisition. Linguistic and Communicative Performance, 2(1), 53-62.

Johnstone, K. (2012). Impro: Improvisation and the theatre. London: Routledge.

Lazar, G. (1993). Literature and language teaching. Cambridge: Cambridge University Press.

Mok, A. (2001). Task-based learning, language arts and the media: A resource book for secondary English teachers. Hong Kong: University of Hong Kong.

Nguyen, P. M., Terlouw, C. \& Pilot, A. (2006). Culturally appropriate pedagogy: the case of group learning in a Confucian Heritage Culture context. International Education, 17 (1), 1-19.

Rodenberg, P. (1998). The actor speaks: Voice and the performer. London: Methuen. 